Article

\title{
Strain Response Characteristics of RC Beams Strengthened with CFRP Sheet Using BOTDR
}

\author{
Ki-Nam Hong ${ }^{1}$, Won-Bo Shim ${ }^{1, *} \mathbb{C}$, Yeong-Mo Yeon ${ }^{1} \mathbb{D}$ and Kyu-San Jeong ${ }^{2}$ \\ 1 Department of Civil Engineering, Chungbuk National University, 1 Chungdae-ro, Seowon-Gu, Cheongju, \\ Chungbuk 28644, Korea; hong@chungbuk.ac.kr (K.-N.H.); yym235@chungbuk.ac.kr (Y.-M.Y.) \\ 2 Sustainable Infrastructure Research Center, Korea Institute of Civil Engineering and Building \\ Technology (KICT), 283, Goyang-daero, Ilsanseo-gu, Goyang-si, Gyeonggi-do 10223, Korea; \\ jungkyusan@kict.re.kr \\ * Correspondence: firstice@chungbuk.ac.kr; Tel.: +82-10-9950-2363
}

Received: 30 July 2020; Accepted: 27 August 2020; Published: 29 August 2020

check for updates

\begin{abstract}
This paper presents the structural behaviors of reinforced concrete (RC) beams that have been strengthened with carbon-fiber-reinforced polymer (CFRP) sheets experimentally and numerically. Test specimens were subjected to four-point bending, and structural behavior was observed using a strain gauge and a Brillouin optical time domain reflectometer (BOTDR) sensor. Non-linear finite element analysis was conducted to examine the applicability and reliability of numerical models using the commercial finite element code, LS-DYNA. In the results, the de-bonded section between the beam substrate and CFRP sheet affected the initial crack in the structure, while the ultimate load, which is related to structural failure, was unaffected. The predicted results correlated well with the experimental observations in terms of the trend of the load-displacement curve, initial crack load, ultimate load and failure mode. Additionally, it is shown that the de-bonding behaviors in the interface were examined using the strain distributions for the CFRP sheets through the experiment and numerical simulations.
\end{abstract}

Keywords: BOTDR; CFRP sheet; un-bonded position; cover delamination; interfacial de-bonding

\section{Introduction}

Reinforced concrete (RC) has recently become one of the most common building materials for social infrastructures. However, RC structures have drawbacks that include a significant reduction to their structural performance over time [1,2]. In the civil engineering community, repairing or strengthening deteriorated RC structures using carbon-fiber-reinforced polymer (CFRP) composites is often done because it is economical and can be constructed in a short amount of time. One popular method for strengthening deteriorated RC structures is attaching CFRP sheets on the external surface of a structure. This method is widely used to improve the loading carrying capacity of the structure with its straight-forward constructability and applicability; it also only causes slight changes in geometry. Additionally, it is applicable to bulk bridge structures, which need continuous strengthening, or a damaged RC structure, since it constrains its damaged parts.

During the last few years, many experimental studies have been performed on the structural behavior of RC beam structures that have been strengthened with external CFRP sheets [3-5]. The structural behavior of the beam structures was affected by the bonded CFRP sheets. The flexural strength and stiffness of the beam structures that were well bonded with CFRP sheets were enhanced [3,4]. However, the RC beam structures that were strengthened with CFRP sheets contained a separation between the concrete surface and the sheet during use. This separation is dangerous in a practical sense, because it can degrade the performance of the composite sheet on the structure 
and affect the load carrying capacity of the beam structure all while being difficult to sight during inspection [2]. Therefore, it is imperative to set up an accurate instrument system to monitor the structural behavior in order to prepare countermeasures.

To measure the deformation of the RC structure and reinforcement member, a conventional electrical resistance strain sensor is widely used. When the conventional strain sensor is used to observe structural deformations in beam structures, multiple sensors or instrumentations are needed because of their short range. The physical quantities, which are measured with the use of electrical devices, are dependent on the surface condition and are unreliable for long term monitoring. Fiber optic sensors (FOS) have been introduced to solve the limitations of the conventional electrical devices. FOS are able to measure physical quantities such as strain and temperature with a high degree of sensitivity, resolution, accuracy and signal-to-noise ratio in a wide range of temperatures [6-9]. These sensors are not only capable of being used in service for long term monitoring $[10,11]$ but can also be applied to the smart instrument technique due to their light weight and small size [12-15]. Woods et al. [16] measured the dynamic behavior of fiber-reinforced polymer strengthened RC shear walls using a distributed fiber optic sensor (DFOS) in the form of the fiber bragg grating (FBG) technique under a cyclic loading condition. It is shown that the DFOS can observe the structural behavior of the concrete member and fiber reinforced polymer. Wu et al. [17] studied the flexural strengthening of a full-scale pre-cast girder that was reinforced with pre-stressed PBO (poly-phenylene benzobisoxazole) sheets using a Brillouin optical time domain reflectometer (BOTDR) under various loading conditions. The BOTDR is one of the fiber optical instruments used, and has been shown to effectively observe the structural behavior of RC beams [18]. While the BOTDR has relatively lower accuracy than the FBG technique, it is effective when applied to the practical bulk structures because of its convenient installation and choices of monitoring point [18].

The objective of this study is to assess the applicability of BOTDR fiber sensors to measure the de-bonding behavior of CFRP sheets on externally strengthened RC structures for their structural integrity. Four-point bending tests were conducted to examine the structural behavior of RC beams that were strengthened with CFRP sheets. The test results were compared with the predicted results, which were provided from a finite element analysis using LS-DYNA. Additionally, the applicability and reliability of the numerical model was examined.

\section{Experiment}

\subsection{Experimental Variable and Manufacturing}

The specimens were manufactured in the form of a wide slab, which provided a large selection of variables and an ease for reinforcement. Figure 1 shows the configuration and dimension of a specimen. With a $30 \mathrm{~mm}$ concrete cover, the specimen was reinforced with 5 SD400-D16 steel bars in a longitudinal direction and SD400-D10 was used for the erection bars and shear stubs with a $200 \mathrm{~mm}$ spacing. Ready mix concrete was used to cast the beam specimens. After the cast was removed, the beam specimens were kept moist for 28 days as a curing period.
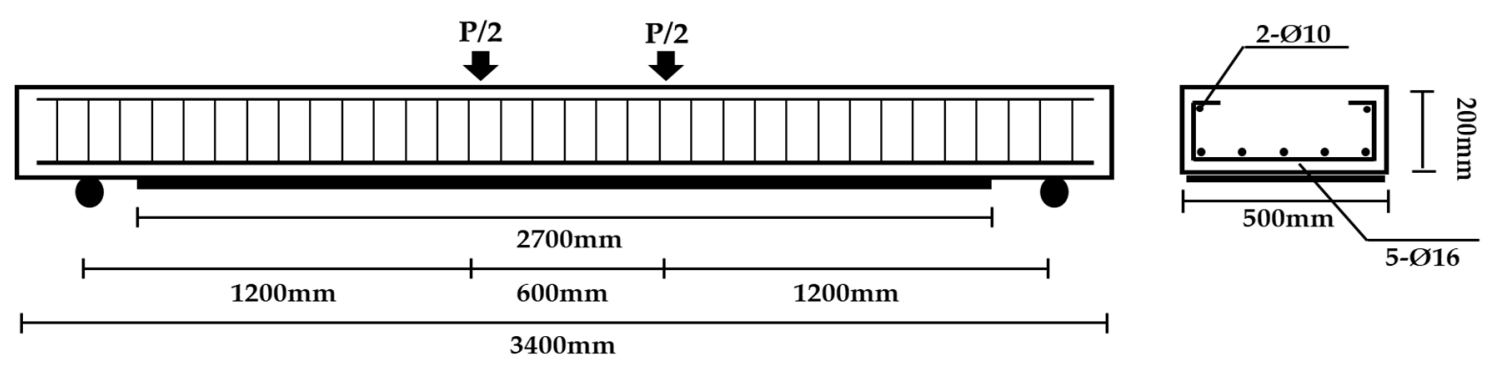

Figure 1. Configuration and dimension of a specimen. 
Primer was spread on the concrete surface to improve the adhesion of the epoxy resin. Plastic films were used to simulate the separation of a CFRP sheet on the specimen. CFRP sheets were attached in two layers using epoxy resin to the tension region of the specimen, which included plastic films. A BOTDR sensor was set up to monitor the behavior of the CFRP sheets on the places where reinforcement was included. Figure 2 shows the geometry of the BOTDR fiber sensor placement. Since signal distortion and breaking can arise when placing a fiber optic sensor on a CFRP sheet, the sensor was attached using a nylon net. Nylon net is lightweight and has low strength, and it can be expected that it will not affect the structural behavior of RC structures. The BOTDR fiber sensor was placed in the arrangement seen in Figure 2, and the total length of the fiber was $27,000 \mathrm{~mm}$. The fiber sensor was fixed on the nylon net using an industrial adhesive tape, and then the nylon net was attached on the concrete substrate using epoxy resin. Finally, the specimen was stored where there was an adequate moisture level and temperature for a curing period of more than 7 days. The experimental variables in this study are presented in Table 1.

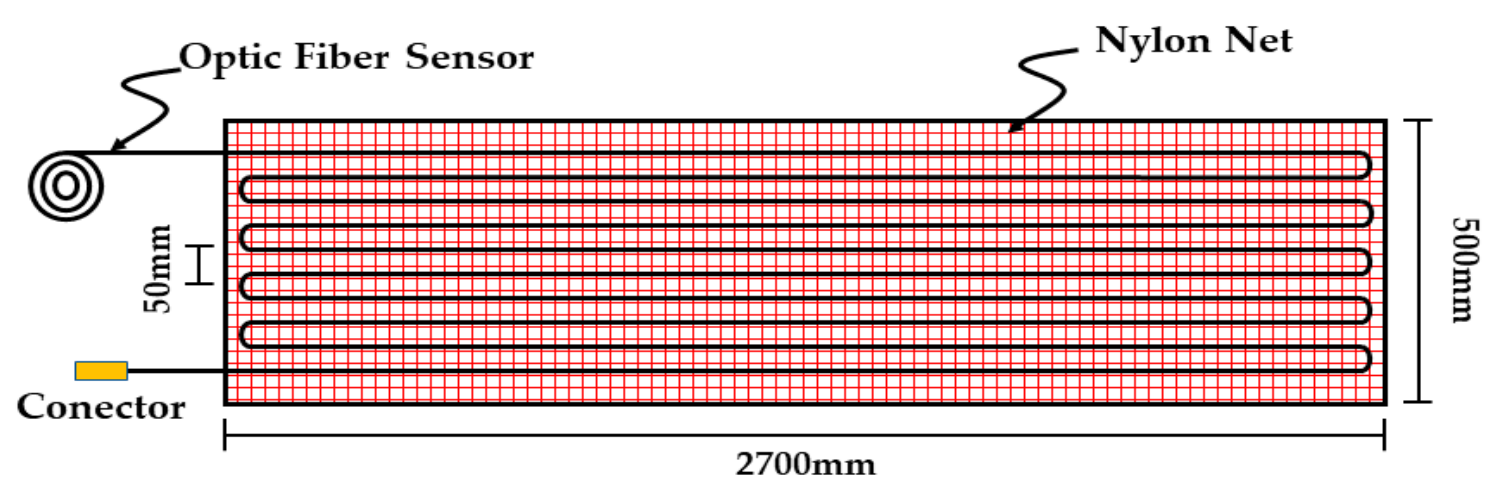

Figure 2. Geometry of the Brillouin optical time domain reflectometer (BOTDR) sensor placement.

\subsection{Loading and Data Acquisition}

The test specimens were subjected to four-point bending using a $2000 \mathrm{kN}$ actuator with displacement control at $1.5 \mathrm{~mm} / \mathrm{min}$. The test specimens were subjected to four-point bending using a $2000 \mathrm{kN}$ actuator with displacement control at $1.5 \mathrm{~mm} / \mathrm{min}$. Since BOTDR fiber sensors can measure the strain in CFRP sheets at a static loading point, the loading was progressively applied and paused at $20 \mathrm{kN}, 60 \mathrm{kN}, 80 \mathrm{kN}, 95 \mathrm{kN}, 110 \mathrm{kN}, 125 \mathrm{kN}$ and $140 \mathrm{kN}$. The static load points were chosen based on the crack load of the concrete substrate and elastic/plastic behavior of the steel bar. After the load reached the ultimate load, it was gradually decreased due to compressive failure in the concrete member and de-bonding/ripping off in the interface. When the load decreased to $80 \%$ of the ultimate load, the tests were terminated. As seen in Figure 3, 2 displacement meters were placed in the middle of the lower surface in order to measure the deflection. In addition, conventional electrical strain gauges were placed in the middle of the specimen. The applied load, deflection and strain values were acquired using a data logger system. 
Table 1. Experimental variable details.

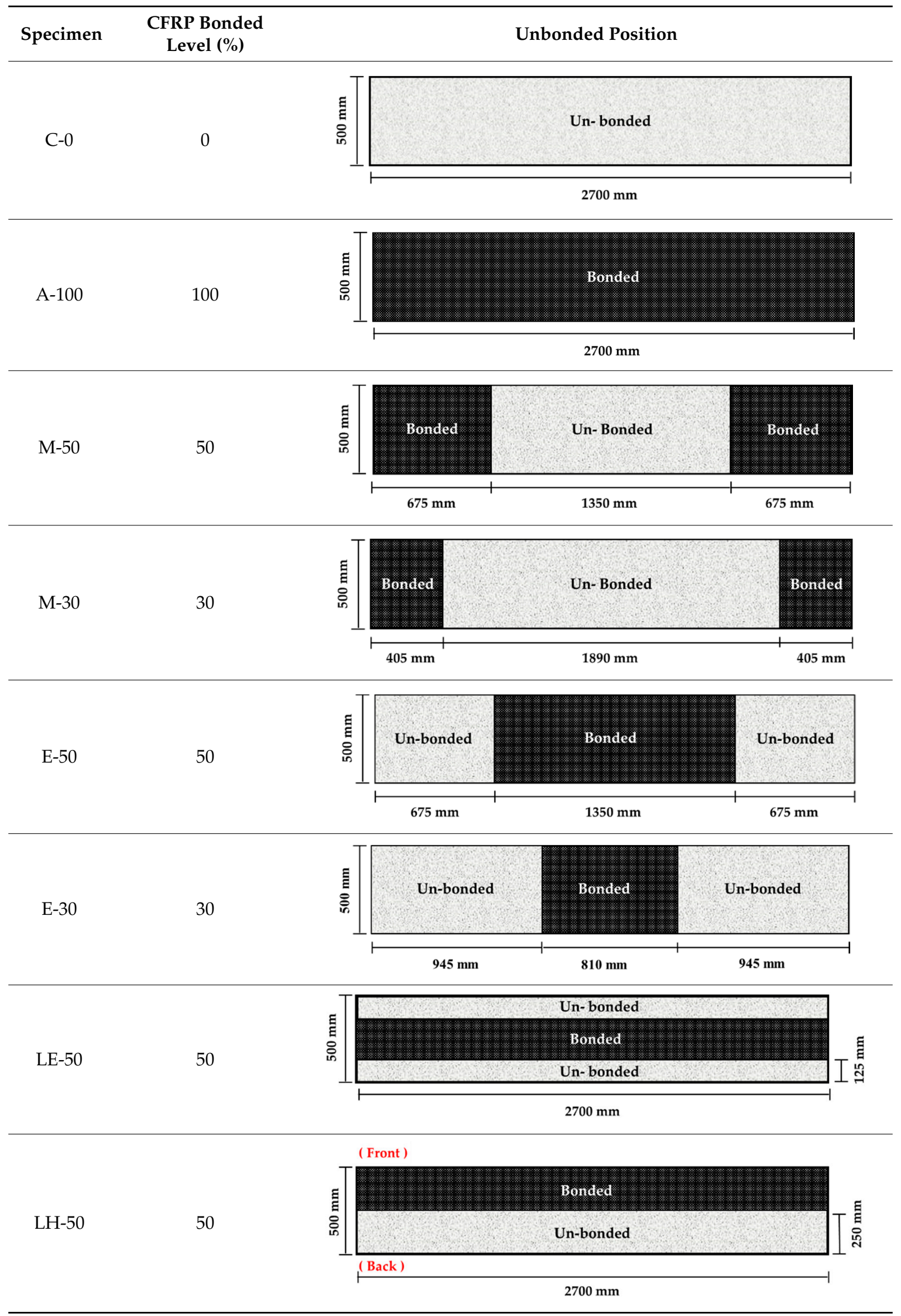




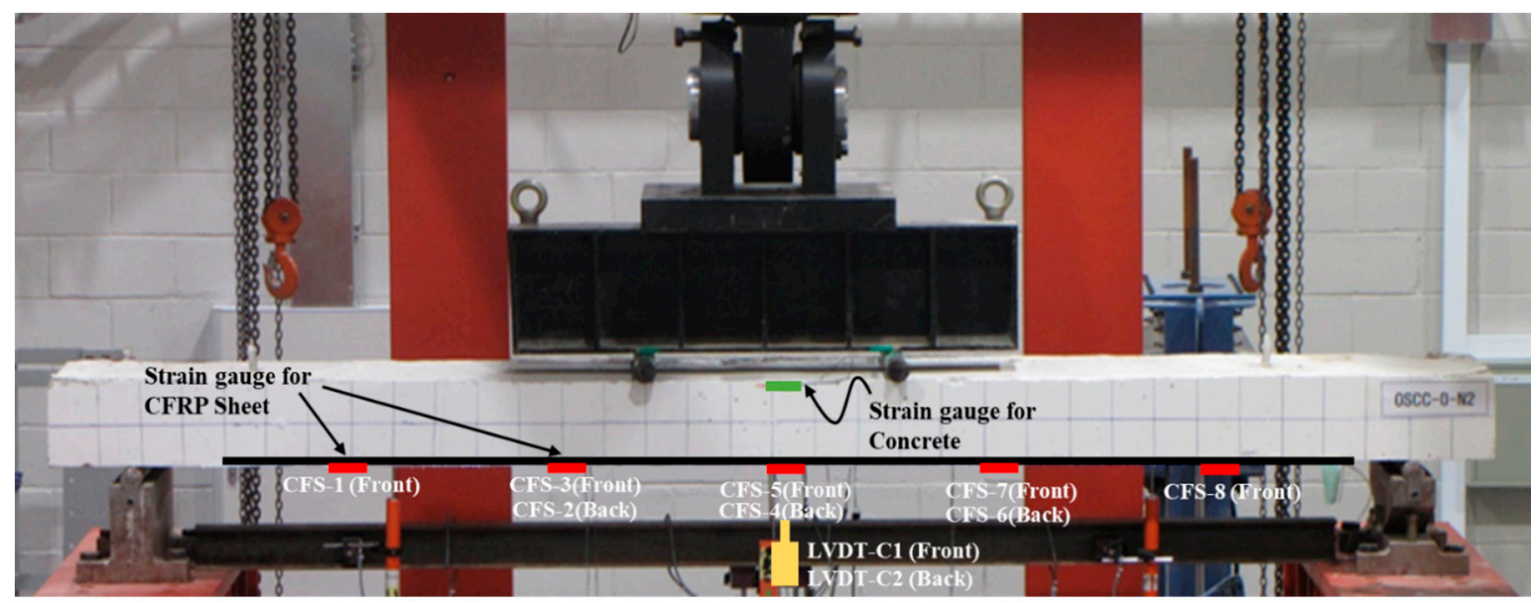

Figure 3. Test setup.

\section{Finite Element Modeling}

\subsection{Analysis}

LS-DYNA, a commercial finite element code, was employed to numerically analyze the behavior of the test specimens. In LS-DYNA, a large selection of material models for concrete, steel and unidirectional composites are equipped and the de-bonding failure along the interface can be simulated using material models and contact modeling [19-21]. In particular, the concrete model reasonably predicts the compressive-stress-adopting element erosion option at the ultimate strength and prevents any stress locking in the post peak region [20,21].

Figure 4 displays the finite element model used in this study. The concrete part was modeled using eight-node volumetric hexagonal solid elements. Two-node Hughes-Liu beam elements were utilized to model the main and transverse steel bars. The CFRP sheet, which was attached to the concrete for strengthening, was modeled using four-node Belytschko-Tsay shell elements. The solid beam and shell elements were approximately $20 \mathrm{~mm}$ in size. The concrete part and steel bars were considered as being perfectly bonded to each other using the LAGRANGIAN_IN_SOLID option.

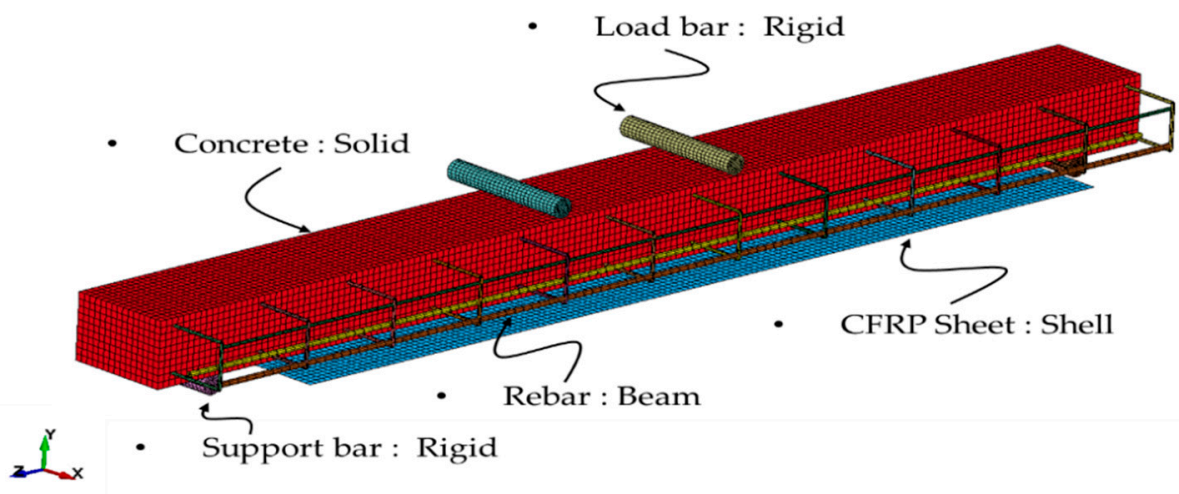

Figure 4. Finite element modeling.

The loading was applied in displacement control and finished when the displacement became $50 \mathrm{~mm}$. Support and loading rods were modeled using rigid elements while avoiding the load concentration around the loading point when the load was directly applied to the element of the concrete material. The contact behavior between the concrete part and rods was considered using the AUTOMATIC_SURFACE_TO_SURFACE contact option. 


\subsection{Material Modeling}

The material properties considered in this study are summarized in Table 2. In general, the concrete material, which is a non-homogenous anisotropic material, represents the nonlinear behavior at a low load level and exhibits different responses in the tension and compression fields. The material model 145, MAT_SCHWER_MURRAY_CAP, was adopted to model the anisotropic nonlinear behavior of the concrete material. Additional strength tests were conducted to determine the compressive strength of the concrete considered in this study using cylindrical nominal specimens. The material parameters for the concrete material were found in Jiang et al. [22].

The material properties for the CFRP sheet and steel bars were taken from the standard material test results. The material model 24, MAT_PIECEWISE_LINEAR_PLASTICITY, was used to model the steel bar. In this material model, the steel exhibits elasto-plastic behavior depending on the arbitrary stress and strain relation. Since the failures in the specimens occurred in the concrete material and the interface, the unidirectional CFRP composite material was considered as an orthotropic elastic material using the material model known as MAT_ORTHOTROPIC_ELASTIC.

Table 2. Material properties.

\begin{tabular}{ccc}
\hline Material & Parameter & Magnitude \\
\hline \multirow{4}{*}{ Concrete } & Material model & MAT_145_SCHWER_MURRAY_CAP_MODEL \\
& Density $\left(\mathrm{kg} / \mathrm{m}^{3}\right)$ & 2320 \\
& Compressive strength $(\mathrm{MPa})$ & 26.0 \\
\hline Max aggregate size $(\mathrm{mm})$ & MAT_024_PIECEWISE_LINEAR_PLASTICITY \\
Steel bar & Material model & 7850 \\
& Density $\left(\mathrm{kg} / \mathrm{m}^{3}\right)$ & 200,000 \\
& Young's modulus $(\mathrm{MPa})$ & 0.3 \\
& Poisson's ratio & 460 \\
& Yield stress (MPa) & 2094 \\
\hline & Tangent modulus (MPa) & 0.1 \\
& Material model & 2400 \\
& Thickness per layer (mm) & 138,000 \\
CFRP Sheet & Density (MPa) & 9650 \\
& Longitudinal modulus (MPa) & 5240 \\
& Transverse modulus (MPa) & 2240 \\
& In-plane shear modulus (MPa) & 0.4 \\
& Out of plane shear modulus (MPa) & 0.021 \\
\hline
\end{tabular}

\subsection{Interface Modeling}

When a bending load is applied to an RC beam strengthening with CFRP, de-bonding failure is one major failure that affects the structural strength. In order to simulate the failure along the interface between the concrete part and CFRP sheet, a large amount of interface modeling was presented [19-21]. In this study, the de-bonding failure between the concrete part and CFRP sheets was modeled using the tiebreak contact option. The tiebreak contact option, TIEBREAK_SURFACE_TO_SURFACE, is one tie contact option in LS-DYNA and works the same as general tie contact options before satisfying the failure criterion. The failure criterion used in this study is presented in Equation (1).

$$
\left(\frac{\left|\sigma_{n}\right|}{N F L S}\right)^{2}+\left(\frac{\left|\sigma_{s}\right|}{S F L S}\right)^{2} \geq 1
$$

where $\sigma_{n}$ is the normal stress, $\sigma_{s}$ is the shear stress, NFLS is the normal failure stress and SFLS is the shear failure stress. Under tensile and shear loads, the normal and shear stresses in the interface are calculated. When the failure criterion is satisfied, the tie contact is released along the interface. 
After failure arises, the interface behaves as a surface to surface contact. In order to simulate the interfacial separation accurately, it is necessary to determine the normal failure stress and shear failure stress through empirical models or proper tensile and shear tests. The failure stresses used in this study were determined through Equations (2)-(4) [23,24]:

$$
\begin{aligned}
& N F L S=0.447\left(f^{\prime}\right)^{0.55} \quad(\mathrm{MPa}) \\
& S F L S=1.5 \beta_{w} N F L S \quad(\mathrm{MPa}) \\
& \beta_{w}=\sqrt{\frac{2.25-b_{f} / b_{c}}{1.25+b_{f} / b_{c}}}
\end{aligned}
$$

where $f^{\prime}$ is compressive strength of the concrete material, $b_{c}$ is center to center spacing of CFRP strips and $b_{f}$ is width of CFRP strip.

\section{Experimental and Numerical Results}

\subsection{Failure Behavior}

The failure behavior of the test specimens under a four-point bending condition was examined using experiments and numerical simulations. Figure 5 presents the failure behavior of the A-100 specimen from the experiment and analysis. The failure occurred in the form of de-bonding failure along the interface between the concrete substrate and the CFRP sheets. This type of failure behavior appeared in the test specimen for M-30, M-50, LE-50 and LH-50. Figure 6 shows the failure behavior of the E-30 specimen. De-bonding failure initiated from the edge of the CFRP sheet along the interface and developed to cover the delamination in the concrete substrate. The failure propagated to the vicinity of where the tensile steel bars were placed. In Figures $5 b$ and $6 b$, the predicted failure behaviors of the test specimens for A-100 and E-30 correlated well with the test results. Additionally, the strain energy distributions in the concrete substrates progressed in accordance with the failure behaviors.

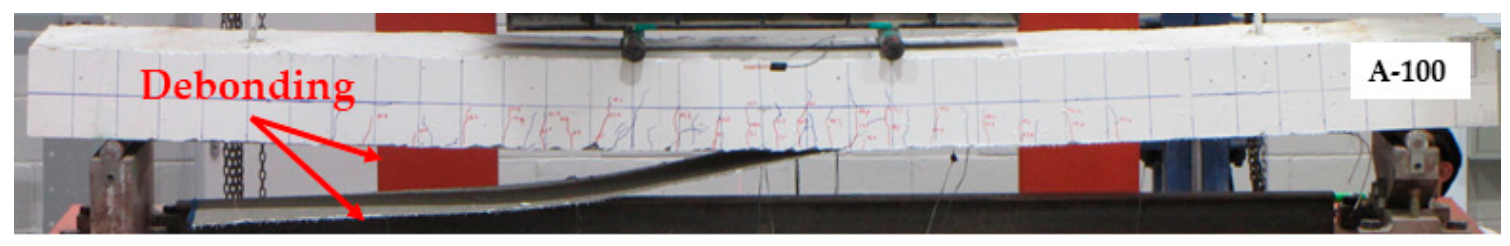

(a)

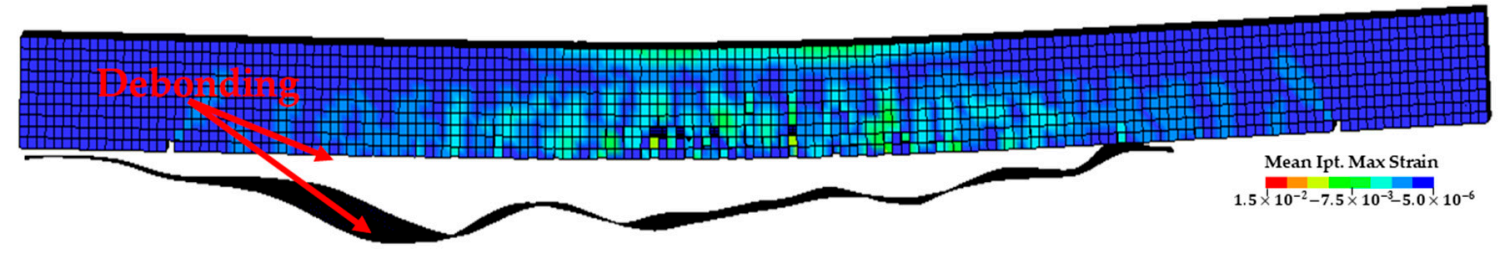

(b)

Figure 5. De-bonding failure mode (A-100). (a) Experiment. (b) Analysis. 


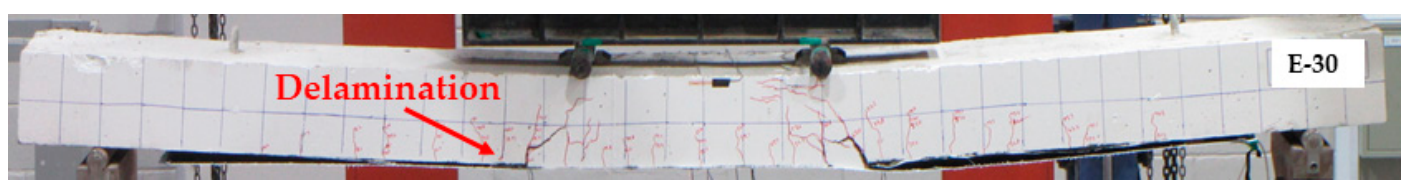

(a)

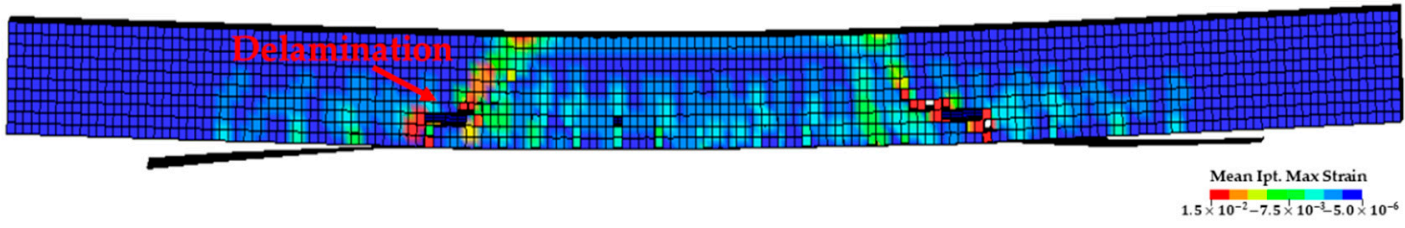

(b)

Figure 6. Delamination failure mode (E-30). (a) Experiment, (b) Analysis.

\subsection{Failure Load and Load-Deflection Response}

The test results are summarized in Table 3. The initial crack loads for the A-100, M-50, E-50, E-30 and LE-50 specimens were higher than the initial crack load for the C-0 specimen. The M-30 and LH-30 specimens were shown to be vulnerable to cracking, because the initial crack loads for the M-30 and LH-50 specimens decreased by $2.01 \%$ and $15.35 \%$, respectively. Additionally, while the initial crack load for the LH-50 specimen, which was strengthened in the front, increased $120 \%$ when compared to the initial crack load for C-0, the initial crack load for the LH-50 specimen, which was strengthened in the back, decreased $15 \%$. This is because the strengthening done using CFRP sheet asymmetrically caused a reduction of load capacity with load eccentricity. However, the ultimate load for all of the specimens varied over $10 \%$ in comparison to the one for the C-0 specimen. It is thought that the un-bond area did not affect the ultimate load of the structure, while the initial crack dominated the un-bonded area of the structure. Nevertheless, it is considered in order to carefully monitor the failures in the RC beam structures because the failure resulted in a reduction of structural performance over a long-term period.

Table 3. Comparison of loads and failure mode *.

\begin{tabular}{|c|c|c|c|c|c|c|c|c|c|c|}
\hline Specimen & $\begin{array}{c}P_{c r . E X} \\
(\mathbf{k N})\end{array}$ & $\begin{array}{l}R_{c r} \\
(\%)\end{array}$ & $\begin{array}{c}P_{u . E X} \\
(\mathrm{kN})\end{array}$ & $\begin{array}{c}P_{u . F E} \\
(\mathbf{k N})\end{array}$ & $\begin{array}{l}P_{u . F E} \\
/ P_{u . E X}\end{array}$ & $\begin{array}{l}R_{u} \\
(\%)\end{array}$ & $\begin{array}{l}\Delta_{u . E X} \\
(\mathrm{~mm})\end{array}$ & $\begin{array}{l}\Delta_{u . F E} \\
(\mathrm{~mm})\end{array}$ & $\begin{array}{c}\Delta_{u . F E} \\
/ \Delta_{u . E X}\end{array}$ & Failure Mode \\
\hline $\mathrm{C}-0$ & 14.46 & 0.0 & 101.62 & 100.52 & 1.01 & 0.0 & 50.02 & 43.51 & 0.87 & Flexural \\
\hline M-50 & 19.74 & 36.51 & 128.98 & 134.42 & 0.96 & 26.92 & 44.43 & 44.95 & 1.01 & Interface De-bonding \\
\hline M-30 & 14.17 & -2.01 & 129.9 & 133.35 & 0.97 & 27.83 & 41.87 & 32.99 & 0.79 & Interface De-bonding \\
\hline E-50 & 27.66 & 91.29 & 122.54 & 125.41 & 0.98 & 20.59 & 50.70 & 51.87 & 1.02 & Cover Delamination \\
\hline LE-50 & 16.69 & 15.42 & 123.54 & 127.82 & 0.97 & 21.57 & 43.19 & 33.35 & 0.77 & Interface Debonding \\
\hline LH-50 & $\begin{array}{l}\text { Front: } 32.12 \\
\text { Back: } 12.24\end{array}$ & $\begin{array}{l}\text { Front: } 122.13 \\
\text { Back: }-15.35\end{array}$ & 114.08 & 128.40 & 0.89 & 12.26 & 34.21 & 36.21 & 1.06 & Interface Debonding \\
\hline
\end{tabular}

${ }^{*} P_{c r . E X}$ : initial crack load; $P_{u . E X}:$ ultimate load of experiment; $P_{u, F E}:$ ultimate load of FEM; $R_{c r}:$ ration of crack load increase compared to the control specimen $(\mathrm{C}-0) ; R_{u}$ : ration of ultimate load increase compared to the control specimen (C-0); $\Delta_{u . E X}$ : midspan deflection of experiment at ultimate load, $\Delta_{u . E X}$ : midspan deflection of FEM at ultimate load.

Figure 7 shows the comparison of the load-deflection curves between the experiments and numerical simulations. While the behavior of the beam structure during the stage where the load was distributed to the steel bars and the CFRP sheet slightly differed, the load-deflection behaviors between the experiment and simulation in terms of the initial slope of the curve, global trend and steel bar yielding point matched well. In the simulation, the ultimate loads were over-predicted by $2 \%$ to $4 \%$. This is reasonably acceptable when it is considered that the beam structure exhibits the 
anisotropic non-linear behavior. In the LH-50 specimen, the predicted ultimate load was approximately $10 \%$ higher than the one from the experiment and the failure behaviors from the experiment and the simulation differed. While the failure occurred along the interface before the steel bars yielded in the experiment, the interface failure appeared after the steel bars yielded. However, it is an insignificant discrepancy since the ultimate loads when the interface failure initiated are comparable in the experiment and simulation. In the case of the E-50 and E-30 specimens, which had concrete ripping off, the maximum deflections in the experiment and the simulation varied within $5 \%$ and the failure behaviors were similar.

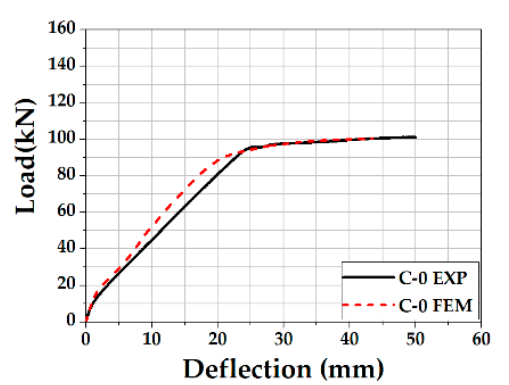

(a)

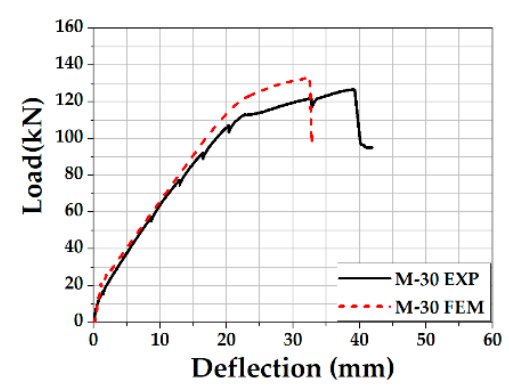

(d)

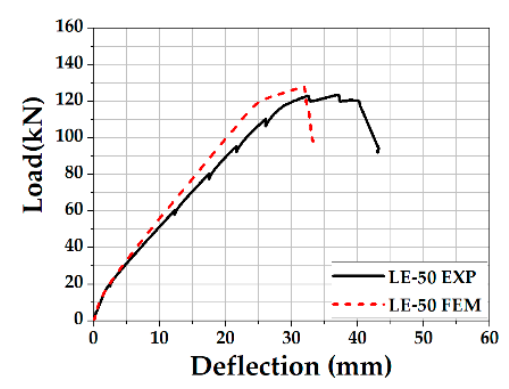

(g)

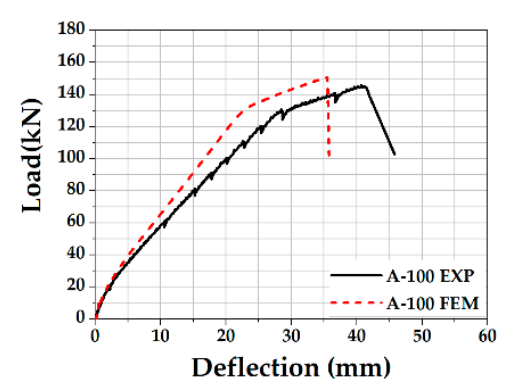

(b)

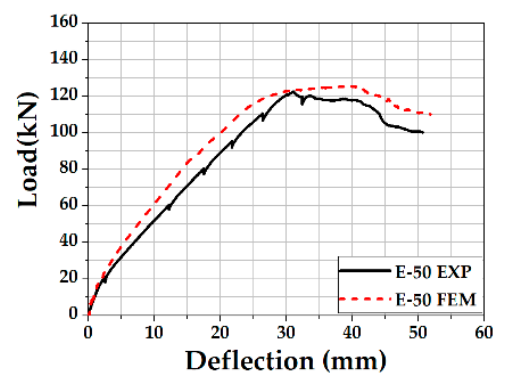

(e)

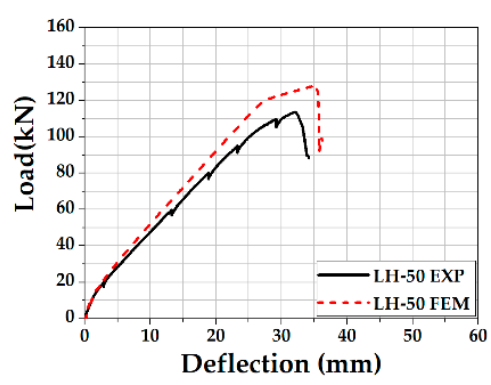

(h)

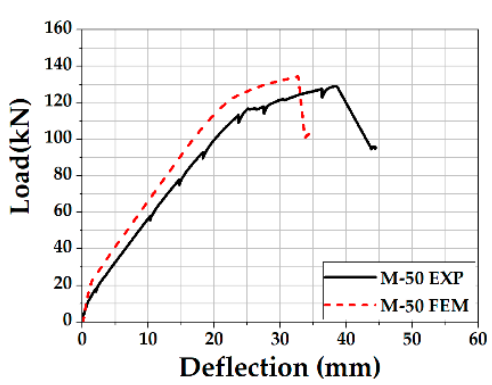

(c)

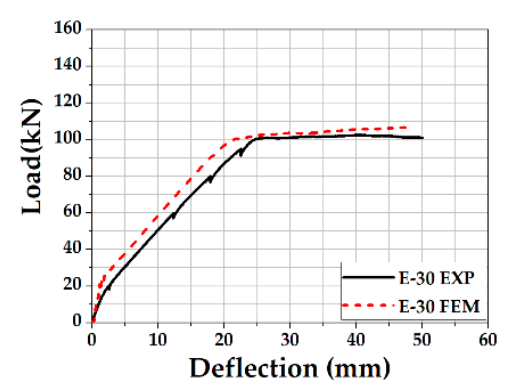

(f)

Figure 7. Comparison of load-deflection curves between experiment and analysis. (a) C-0, (b) A-100, (c) M-50, (d) M-30, (e) E-50, (f) E-30, (g) LE-50, and (h) LH-50.

\subsection{Strain Behavior of CFRP Sheet}

The ultimate strain results in the middle of the CFRP sheets from the experiments and numerical simulations are summarized in Table 4. In the experiment, the strain was monitored using two types of instruments: a conventional electrical strain gauge and a BOTDR sensor. When using the strain gauge, the ultimate strain for the M-30 specimen, which had an unbound area in the middle of the beam structure, was $30 \%$ lower than the one for the A-100 specimen, which was strengthened perfectly. It is shown that placing the strengthening CFRP sheets in the middle of the beam structure results in a more advantageous performance of the CFRP sheets on the structural behavior. In the simulation, 
the ultimate strains were slightly over-predicted by $15 \%$ in contrast to those from the strain gauges. The ultimate strains that were monitored using the BOTDR sensors were 17\% lower than those from the strain gauges.

Figure 8 presents the comparison of the load-strain curves in the experiment and analysis in the CFRP sheet. In most cases, the predicted load-strain behaviors corresponded well with the observed loads and strains when using the strain gauges and BOTDR sensors. The slopes of the load-strain curves in the numerical simulation were relatively lower than those in the experiments. It is thought that the difference of the slopes in the numerical simulation and experiments was a result of the measuring conditions in the experiments. The strain from the strain gauge affected the surface condition where the strain gauge was placed and could be roughly measured due to the adhesive epoxy. In the case of the BOTDR sensor, the strain was considered to be more stable than the one that was from the strain gauge because the sensor was perfectly bonded with the CFRP sheet and the strain result's average value was in the range of $500 \mathrm{~mm}$. Therefore, it was found that the numerical results were relatively close to the experimental results using the BOTDR sensor. The load-strain response seen in Figure 8e from the BOTDR sensor shows the difference with other curves. Considering the fact that it happened only in the E-30 specimen and the load-deflection response for the E-30 specimen were reasonable, it is thought to be caused by the slip of the BOTDR fiber sensor which needed to be fully constrained in the epoxy during the experiment.

Table 4. Comparison of the strains in the carbon-fiber-reinforced polymer (CFRP) sheet.

\begin{tabular}{cccccc}
\hline Specimen & \multicolumn{3}{c}{ CFRP Strain $(\mu \epsilon)$} & Gauge/FEM & Gauge/BOTDR \\
\hline & Gauge & FEM & BOTDR & & \\
A-100 & 6035.70 & 6114.95 & 4261.06 & 0.99 & 1.42 \\
M-50 & 2867.61 & 4113.02 & 3190.17 & 0.70 & 0.90 \\
M-30 & 1896.72 & 2810.13 & 459.20 & 0.67 & 4.13 \\
E-50 & 2407.52 & 2952.68 & 2106.83 & 0.82 & 1.14 \\
E-30 & 3405.64 & 2998.07 & 2482.14 & 1.14 & 1.37 \\
LE-50 & 4594.38 & 5347.05 & 3056.74 & 0.86 & 1.50 \\
LH-50 & 2877.01 & 3908.65 & 3967.69 & 0.74 & 0.73 \\
\hline
\end{tabular}

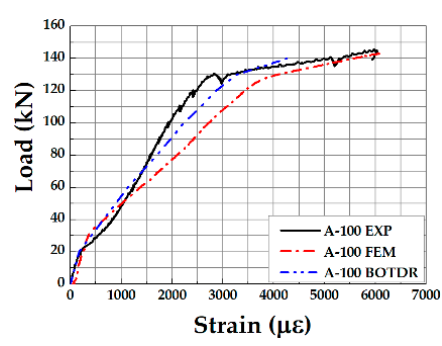

(a)

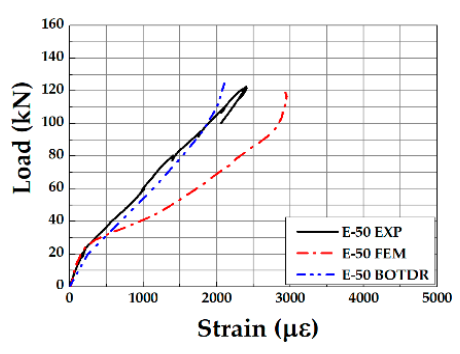

(d)

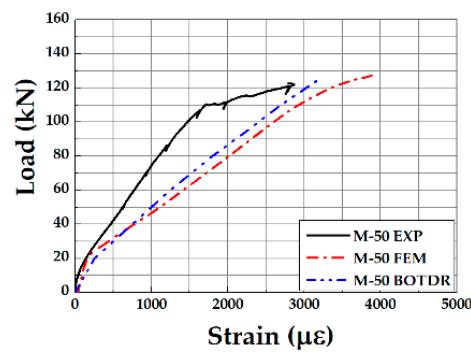

(b)

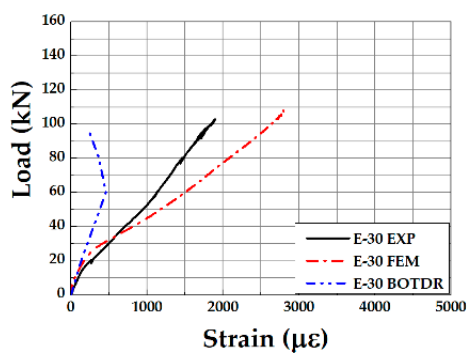

(e)

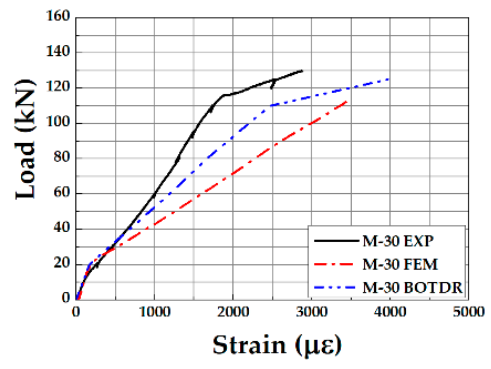

(c)

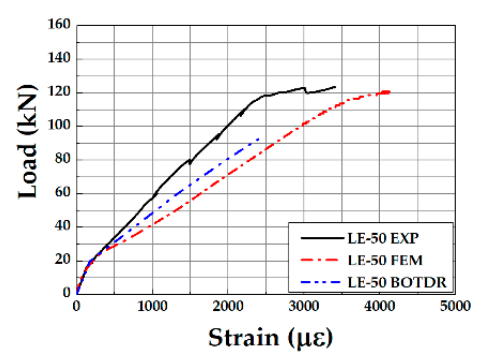

(f)

Figure 8. Cont. 


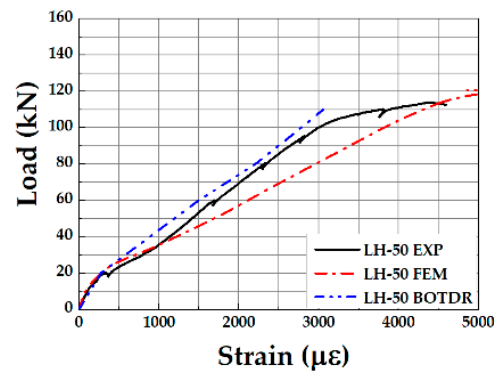

(g)

Figure 8. Comparison of load-strain curves between experiment and analysis in the CFRP sheet. (a) A-100, (b) M-50, (c) M-30, (d) E-50, (e) E-30, (f) LE-50, and (g) LH-50.

In addition, the strain distribution for the CFRP sheets was investigated using the strain results through the BOTDR sensors and numerical simulations. The strain distributions that used experimental strain results were visualized using Origin, a numerical analysis program. In the visualization, the strain distributions were classified in 8 levels following the order of the magnitude and a thin plate spline algorithm was utilized to improve the visibility. Figure 9 shows the strain distribution of the CFRP sheet in the A-100 specimen from the experiment and simulation. As seen in Figure 9, the predicted strain distribution matched well with the experimental result in terms of the magnitude of the strain and the shape of the strain distribution. In the experimental result, the high strain region was relatively narrower than the one from the simulation. It is thought that the resolution of the experimental results is insufficient to present the accurate strain distribution. Figure 10 presents the strain distribution of the CFRP sheet in the M-50 specimen. The numerical result correlated well with the experimental result. While the shape of the developed strain in the CFRP is similar to the one in the A-100 specimen, the magnitude of the strain in the middle of the CFRP sheet was relatively lower. This is because the M-50 specimen included the un-bonded region between the CFRP and concrete substrate in the middle of the beam structure.

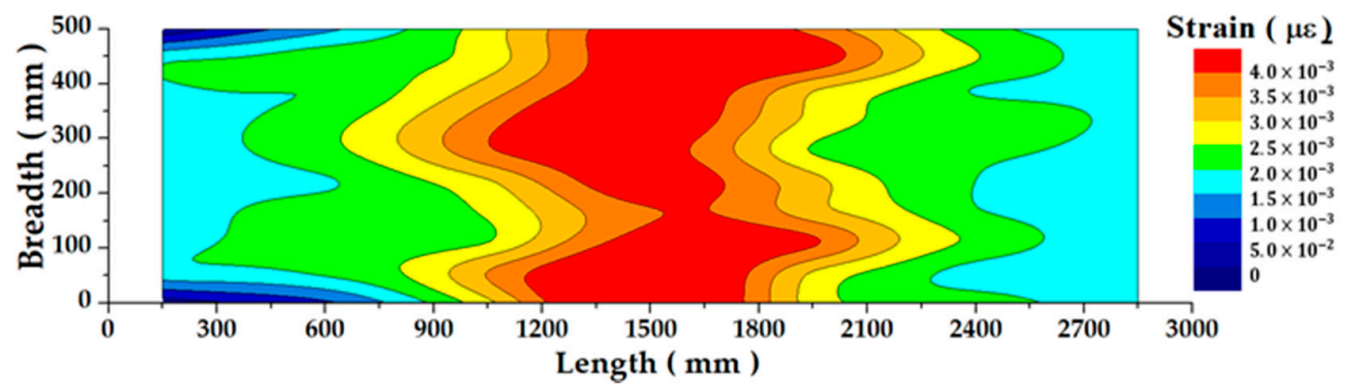

(a)

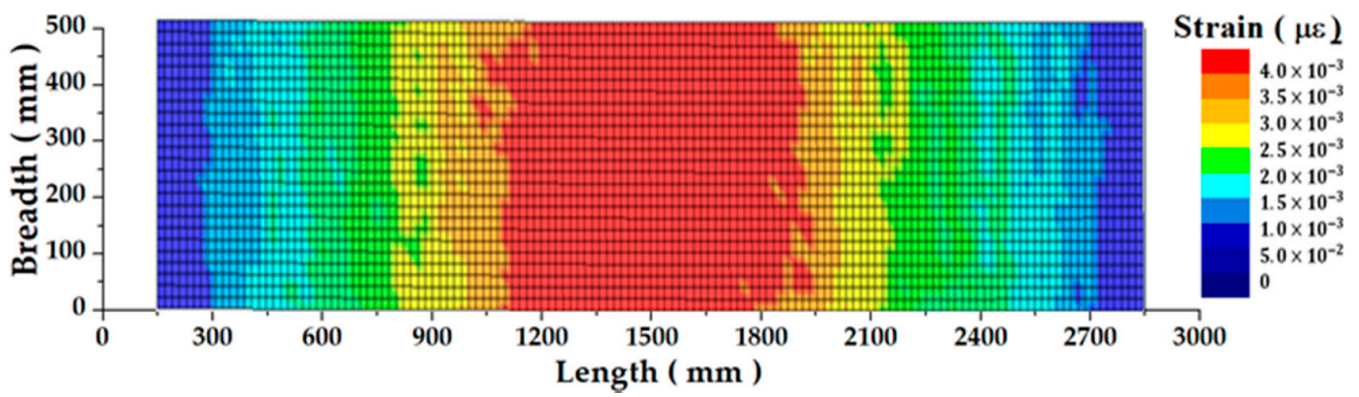

(b)

Figure 9. Comparison of CFRP strain distributions using BOTDR sensor and analysis (A-100). (a) BOTDR, (b) FEM. 


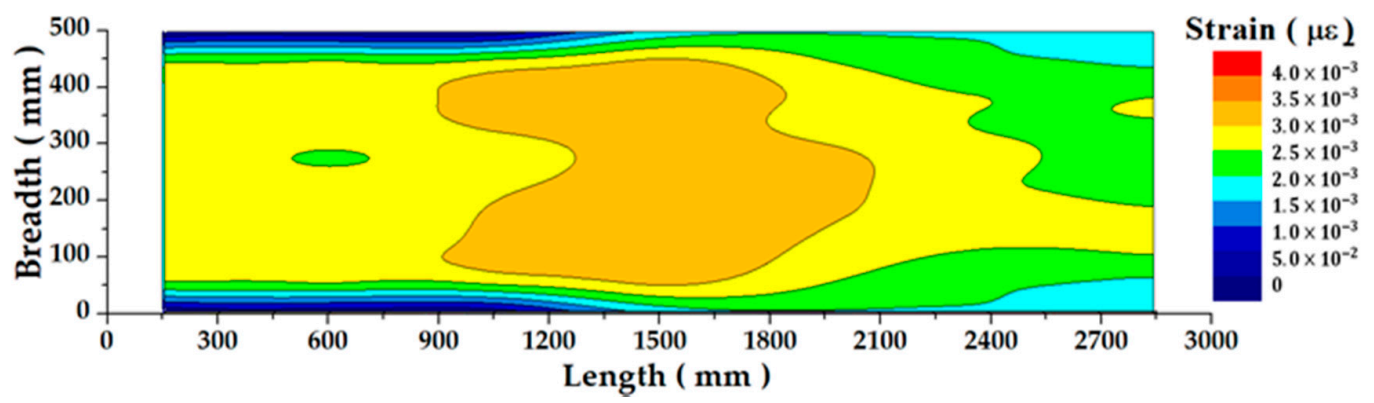

(a)

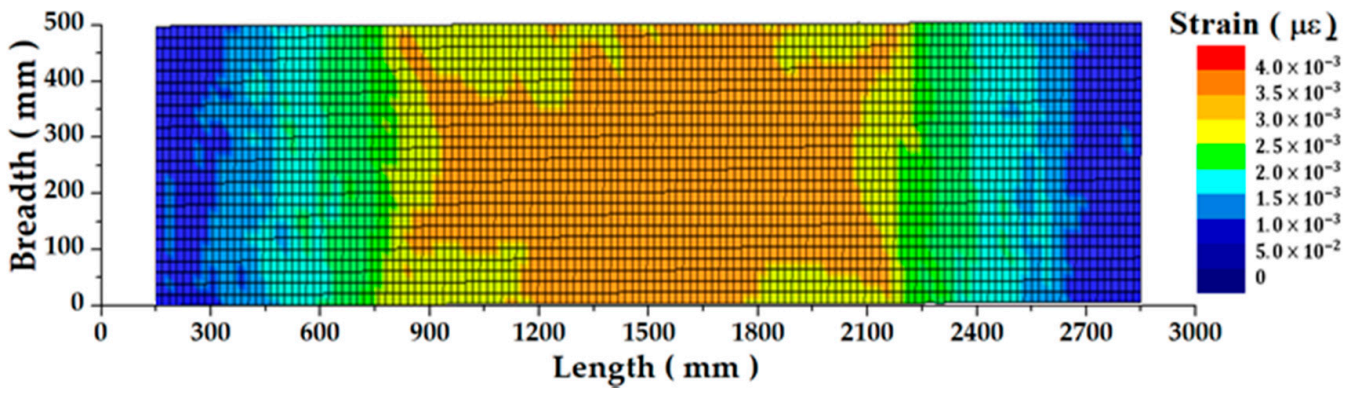

(b)

Figure 10. Comparison of CFRP strain distributions using BOTDR sensor and analysis (M-50).

(a) BOTDR, (b) FEM.

The strain distribution of the CFRP sheet in the E-30 specimen is displayed in Figure 11. The strain did not develop at the end of the CFRP sheet and grew in the middle where the CFRP sheet and the concrete substrate were bonded. As with the two cases described above, the numerical simulation predicted the strain distribution of the CFRP sheet reasonably.

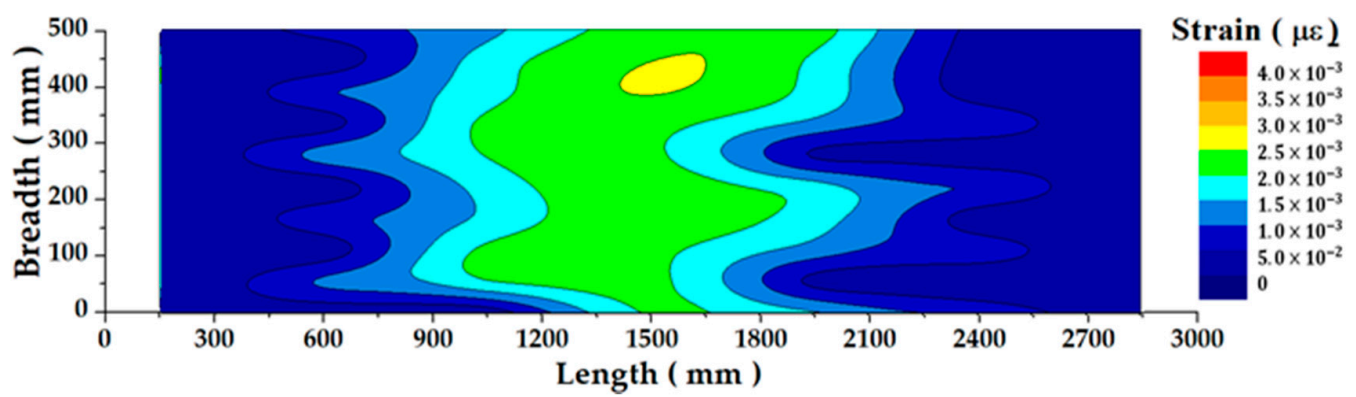

(a)

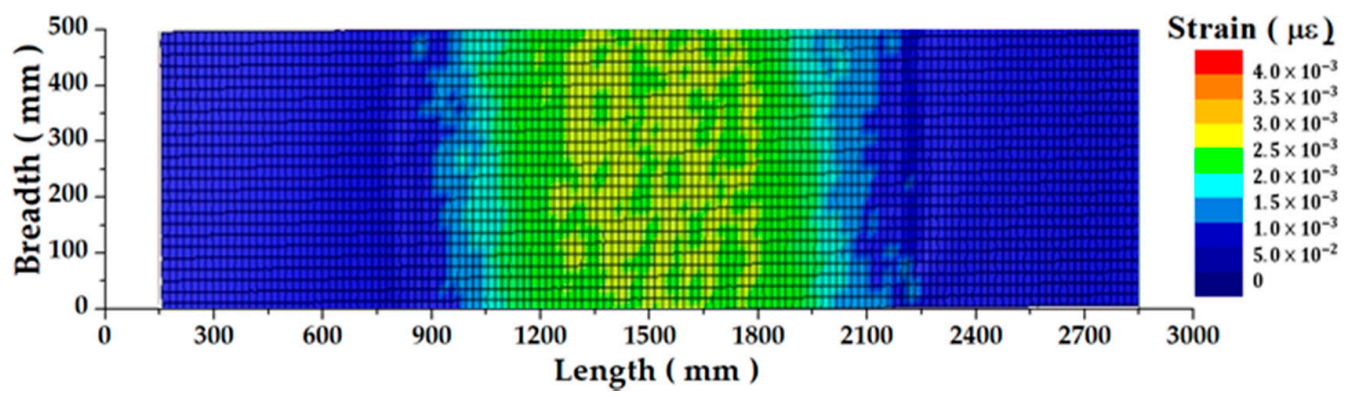

(b)

Figure 11. Comparison of CFRP strain distributions using BOTDR sensor and analysis (E-50). (a) BOTDR, (b) FEM. 


\section{Conclusions}

In this study, the structural behavior of RC beams that had been strengthened with CFRP sheets was monitored using a BOTDR fiber sensor experimentally. Additionally, a numerical simulation was performed using LS-DYNA, a commercial non-linear finite element analysis program, and compared with the simulation from the experiment. The conclusions are described below:

(1) The de-bonding behavior between the concrete substrate and CFRP sheets affected the initial crack in the structure, while the ultimate load, which was related to the structural failure, was unaffected. Nonetheless, it is necessary to cautiously monitor the failures in RC beam structures because any failure could lead to a reduction in structural performance over a long period of time.

(2) The strain distribution for the CFRP sheets can be visualized using the strain results through the BOTDR sensor, and it allows for a decent investigation of the de-bonding behavior of the CFRP sheets on the concrete substrate.

(3) The numerical simulation correlated well with the experimental results in terms of the failure mode, failure pattern and the position where the de-bonding occurred. Therefore, it is possible to utilize the numerical simulation to study the de-bonding behavior of RC structures that are strengthened with CFRP sheets.

(4) The strain results from the BOTDR fiber sensor and numerical simulation are considered to be stable and well matched, while the strain result from the strain gauge is relatively unstable because the strain gauge affected the surface condition where the gauge was placed. Therefore, it is thought that the BOTDR fiber sensor is more reliable when monitoring the RC structure than the conventional strain gauge.

Author Contributions: K.-N.H. and W.-B.S. conceptualized the study; W.-B.S. obtained field data; W.-B.S. and Y.-M.Y. implemented data processing under the supervision of K.-N.H.; the original draft of the manuscript was written by K.-N.H. and W.-B.S. with editorial contributions from Y.-M.Y. and K.-S.J. All authors have read and agreed to the published version of the manuscript.

Funding: This paper work was financially supported by Ministry of the Interior and Safety as Human Resource Development Project in Disaster Management.

Conflicts of Interest: The authors declare no conflict of interest.

\section{References}

1. Lim, D.H. An Experimental Study of Flexural Strengthening Method of Reinforced Concrete Beams with Near Surface Mounted CFRP Strips. J. Korean Soc. Civ. Eng. 2013, 33, 131-136. (In Korean) [CrossRef]

2. Park, J.-S.; Kim, B.-C.; Park, K.-T.; Jung, K.-S. Analytical Study on the Bond Performance of Fiber Optic Sensor Embedded Carbon Fiber Sheets for Strengthening Concrete Structures. J. Korean Soc. Adv. Compos. Struct. 2018, 9, 31-36. (In Korean) [CrossRef]

3. Toutanji, H.; Zhao, L.; Zhang, Y. Flexural behavior of reinforced concrete beams externally strengthened with CFRP sheets bonded with an inorganic matrix. Eng. Struct. 2006, 28, 557-566. [CrossRef]

4. Li, Y.-F.; Xie, Y.-M.; Tsai, M.-J. Enhancement of the flexural performance of retrofitted wood beams using CFRP composite sheets. Constr. Build. Mater. 2009, 23, 411-422. [CrossRef]

5. Khan, A.U.R.; Fareed, S. Behaviour of Reinforced Concrete Beams Strengthened by CFRP Wraps with and without End Anchorages. Procedia Eng. 2014, 77, 123-130. [CrossRef]

6. Lee, D.G.; Mitrovic, M.; Friedman, A.; Carman, G.P.; Richards, L. Characterization of Fiber Optic Sensors for Structural Health Monitoring. J. Compos. Mater. 2002, 36, 1349-1366. [CrossRef]

7. Todd, M.D.; Nichols, J.M.; Trickey, S.T.; Seaver, M.; Nichols, C.J.; Virgin, L.N. Bragg grating-based fiber optic sensors in structural health monitoring. Philos. Trans. R. Soc. A 2007, 365, 317-343. [CrossRef]

8. Ansari, F. Practical Implementation of Optical Fiber Sensors in Civil Structural Health Monitoring. J. Intell. Mater. Syst. Struct. 2007, 18, 879-889. [CrossRef]

9. Deng, L.; Cai, C.S. Applications of fiber optic sensors in civil engineering. Struct. Eng. Mech. 2007, 25, 577-596. [CrossRef] 
10. Casas, J.; Cruz, P.J.S. Fiber Optic Sensors for Bridge Monitoring. J. Bridg. Eng. 2003, 8, 362-373. [CrossRef]

11. Betz, D.C.; Staudigel, L.; Trutzel, M.N.; Kehlenbach, M. Structural Monitoring Using Fiber-Optic Bragg Grating Sensors. Struct. Health Monit. 2003, 2, 145-152. [CrossRef]

12. Zhan-Feng, G.; Yan-Liang, D.; Bao-Chen, S.; Xiu-Mei, J. Strain monitoring of railway bridges using optic fiber sensors. J. Qual. Maint. Eng. 2007, 13, 186-197. [CrossRef]

13. Doyle, C.; Staveley, C.; Henderson, P. Structural health monitoring using optical fiber strain sensing systems. In Proceedings of the 4th International Workshop on Structural Health Monitoring, Stanford, CA, USA, 1 July 2003; Volume 1, pp. 1-8.

14. Maalej, M.; Rizkalla, S.H. Fiber optic sensing and intelligent processing of sensor data for structural health monitoring. In Proceedings of the 14th International Conference on Optical Fiber Sensors, Island of San Giorgio Maggiore, Venice, Italy, 11-13 October 2000; Volume 4185, pp. 238-241.

15. Li, S.; Wu, Z. Development of Distributed Long-gage Fiber Optic Sensing System for Structural Health Monitoring. Struct. Health Monit. 2007, 6, 133-143. [CrossRef]

16. Woods, J.; Lau, D.; Bao, X.; Li, W. Measuring strain fields in FRP strengthened RC shear walls using a distributed fiber optic sensor. Eng. Struct. 2017, 152, 359-369. [CrossRef]

17. Wu, Z.; Xu, B.; Hayashi, K.; Machida, A. Distributed optic fiber sensing for a full-scale PC girder strengthened with prestressed PBO sheets. Eng. Struct. 2006, 28, 1049-1059. [CrossRef]

18. Kim, B.-C.; Jung, K.-S.; Park, J.-S.; Park, K.-T. Brillouin-OTDR Strain Response Analysis of Optical Fiber-embedded Carbon Fiber Sheet. J. Korean Soc. Adv. Compos. Struct. 2018, 9, 1-8. [CrossRef]

19. Hussein, M.E.; Tarek, H.A.; Saleh, H.A.; Yousef, A.A. Experimental and FE study on RC one-way slabs upgraded with FRP composites. J. Korean Soc. Civil. Eng. 2011, 31, 399-408.

20. Yoo, D.-Y.; Min, K.-H.; Lee, J.-Y.; Yoon, Y.-S. Evaluating Impact Resistance of Externally Strengthened Steel Fiber Reinforced Concrete Slab with Fiber Reinforced Polymers. J. Korea Concr. Inst. 2012, 24, $293-303$. [CrossRef]

21. Li, L.; Lee, J.Y.; Min, K.H.; Yoon, Y.-S. Evaluating Local Damages and Blast Resistance of RC Slabs Subjected to Contact Detonation. J. Korea Inst. Struct. Maint. Insp. 2013, 17, 37-45. [CrossRef]

22. Jiang, H.; Zhao, J. Calibration of the continuous surface cap model for concrete. Finite Elem. Anal. Des. 2015, 97, 1-19. [CrossRef]

23. Lu, X.; Teng, J.; Ye, L.; Jiang, J. Bond-slip models for FRP sheets/plates bonded to concrete. Eng. Struct. 2005, 27, 920-937. [CrossRef]

24. Lu, X.; Teng, J.; Ye, L.P.; Jiang, J.J. Intermediate Crack Debonding in FRP-Strengthened RC Beams: FE Analysis and Strength Model. J. Compos. Constr. 2007, 11, 161-174. [CrossRef] 